\title{
Hazy reasoning behind clean air
}

\section{Science alone can't determine how regulations are written, argues David Goldston.}

ast month, The Washington Post reported that President George W. Bush had - personally intervened to weaken new regulations to control smog just as they were about to be announced by the Environmental Protection Agency (EPA). In response, advocates of tighter standards predictably charged that the president had overturned a scientific judgement. Carol Browner, who headed the EPA under President Bill Clinton, put the matter starkly, telling the Post that the Clean Air Act creates "a moral and ethical commitment that we're going to let the science tell us what to do".

But does it? This conceit that science alone should and can dictate clean-air standards is propagated by political figures of all stripes and often by scientists themselves. Politicians always want to argue that any regulatory measure they are supporting is the only one justified by science because doing so makes their position sound objective and above the political fray. That's especially true in today's polarized environment, when claiming to have science on your side may be the only line of argument that can reach someone who doesn't share your ideological persuasion.

In reality, though, regulatory decisions involve policy judgements as well as scientific determinations, and the science is often uncertain. The Clean Air Act explicitly leaves decisions to the "judgment of the administrator" of the EPA (a presidential appointee), who is advised by, among others, a scientific panel. Contending that standards are based solely on science conflates policy and science questions, muddying the debate and putting scientists needlessly in the line of fire.

So what's really at issue in the case of the smog rules? The rule the president changed sets what is known as the secondary standard for allowable concentrations of ground-level ozone, the main component of smog. Under the law, the secondary standard is designed to "protect the public welfare" by preventing damage to crops, natural vegetation and anything else other than "public health", which is covered by the primary standard.

The EPA's 24-member scientific advisory panel weighed in on two critical questions concerning the secondary standard: over what time period should ozone be measured, and what should the permissible level of ozone be? The first question may sound like a technicality, but it affects which

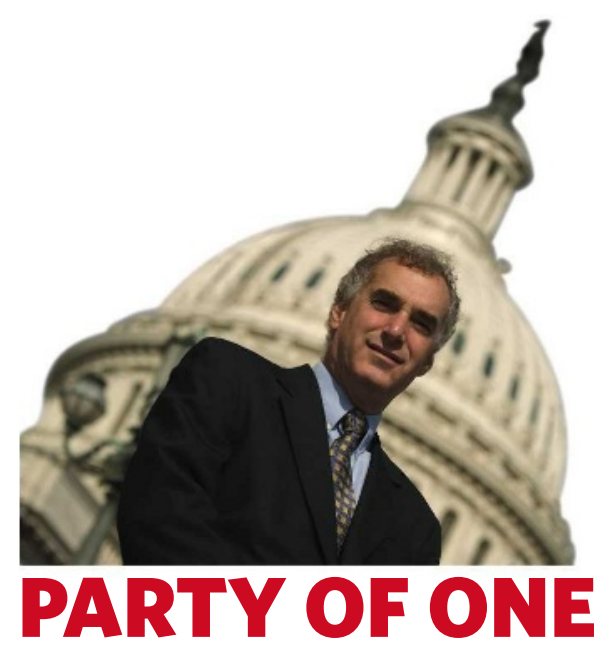

areas turn out to violate the standard because ozone levels can vary significantly within a given day. For example, if being above the allowable level for even one hour on one day is a violation, then places may be required to clean up their air that wouldn't if the rule forbade exceeding that same standard over an eight-hour average on a single day.

The time period is supposed to be based on biology. If being exposed to ozone for even one hour can have a substantial impact, then that should be the time period used. The advisory committee said unanimously and unequivocally that plants are affected by ozone through cumulative exposure over an entire growing season - so the existing eight-hour period, which is based on how ozone affects humans, is inappropriate. The president left the eighthour period in place, which clearly runs counter to the science. For that piece of the rule, he should be considered guilty as charged.

But the other piece is deciding what level of ozone should be permitted, and that cannot be determined solely by science for two reasons. First, deciding what level of damage constitutes a threat to "public welfare" inherently is not a scientific question. Scientists may be able to describe the damage that could result from a given level of ozone, but the decision that such damage is so great that it must be prevented is a policy matter.

Second, the EPA's science panel found that "quantitative evidence linking specific ozone concentrations to specific vegetation/ecological effects must ... be characterized as having high uncertainties." What to do in the face of uncertainty is a policy question, not a scientific question. So although the advisory panel unanimously recommended a specific range of ozone standards, a number within that range can hardly be seen as the only justifiable standard under the law. Indeed, the EPA's own science staff had recommended a slightly different range. Critics are free to attack the number chosen by the president, which will keep some rural counties in compliance with clean-air rules. What they cannot legitimately argue is that the president's selection runs counter to the science. The debate is about what kinds of damage harm the public welfare and what kinds of uncertainty can be tolerated as a basis for decision-making.

The debate over the new ozone standards is just beginning, but the detrimental impact of confusing science with policy can be seen by looking back at what happened in 1997, when the EPA last changed the ozone rules. The fight then was over the primary ozone standard, the one designed to protect public health. The EPA proposed tightening the standard, and Browner (then EPA's chief) repeatedly argued that the decision was dictated by the science.

As a congressional staffer, I fought for the EPA proposal and I still support it. But what the science actually demonstrated was that for a given level of ozone, there are a predictable number of excess hospital admissions from aggravated respiratory conditions. At the time, there was little indication that ozone caused chronic health problems or deaths. Therefore the policy issue was: "How many hospital admissions are acceptable?" Needless to say, no politician was interested in engaging in that debate. The members of the EPA's science advisory panel at the time were split over what standard to suggest, but agreed that the number was a "policy call", not a scientific question. The science in no way told Browner exactly what to do.

All this quickly got lost in what became a prolonged and highly acrimonious debate between supporters and opponents of the new rule, in which each side accused the other of using poor science. This was bad for policy because the question of how to decide on an acceptable level of protection never got raised, never mind discussed. And it was bad for science because accusations of poor science conducted in the service of political goals can only raise distrust and confusion about the scientific enterprise.

The 1997 ozone fight, even more clearly than the 2008 rerun, was a case of a policy debate masquerading as a science debate. In such instances, scientists ought to be busy ripping off the policymakers' masks, not donning them.

David Goldston is a visiting lecturer at Harvard University's Center for the Environment. Reach him at partyofonecolumn@gmail.com. 